\title{
Compositional Analysis of Magnetic Crystal Grains in a CoCrPt-SiOx Perpendicular Recording Medium
}

\author{
T. Handa, Y. Takahashi*, R. Araki*, and M. Futamoto \\ Faculty of Science and Engineering, Chuo Univ., Kasuga 1-13-27, Bunkyo-ku, Tokyo 112-8551, Japan \\ ${ }^{*}$ Central Research Laboratory, Hitachi, Ltd., Higashi-koigakubo 1-280, Kokubunji, Tokyo 185-8601, Japan
}

\begin{abstract}
The diameter and composition of magnetic crystal grains in a $\mathrm{CoCrPt}_{-} \mathrm{SiO}_{\mathrm{x}}$ perpendicular magnetic recording medium were investigated by using a transmission electron microscope (TEM) equipped with an energy-dispersive $\mathrm{X}$-ray spectrometer (EDX). It has been shown that the composition of individual grains depends little on the grain diameter. The variations in the uniaxial anisotropy constant $\left(K_{\mathrm{w}}\right)$, the saturation magnetization $\left(M_{\mathrm{s}}\right)$, and the anisotropy field $\left(H_{\mathrm{k}}\right)$ are estimated from the composition for individual magnetic crystal grains. The thermal stability of magnetic crystal grains is discussed on the basis of the estimated $K_{\mathrm{u}} V / k T$ values on the assumption that the magnetic crystal grains are magnetically separated.
\end{abstract}

Key words: CoCrPt-SiOx, perpendicular recording media, microstructure, composition, transmission electron microscope, thermal stability.

\section{CoCrPt-SiOx垂直磁気記録媒体における磁性結晶粒の組成解析 半田貴洋・高橋由夫* ·荒木亮子* 二本正昭 \\ 中央大学理工学部, 東京都文京区春日 1-13-27 ( ₹ 112- 8551) \\ *日立製作所中央研究所，東京都国分寺市東恋ヶ窪 1- 280 (广 185-8601)}

1.はじめに

高密度磁気記録を行うためには記録媒体を構成する磁生結晶粒 の微細化，均一化力必要であり，透過電子顕微鏡 (TEM) を用い た垂直磁気記録媒体の微細組織の観察力゙行われている1-3) . また， 記録媒体の磁気特性力磁生結晶粒の組成に強く依存することを考 慮して, 結晶粒才ーダーての組成分析力試みられている 記録媒体の熱媱らき特性は，一軸磁気異方性定数 $K_{\mathrm{u}}$ と結晶粒体積 り積 $K \mathrm{u}$ Иこ依存するが，Иは粒径に，Kuは粒組成に依存する。こ れまて粒径分布9-11)やCoCrPt系媒体内の粒内組成,8, を調べた研究 力報告されている、磁気記録某体の結晶粒レベルの熱摇らき特性 を検討するためには，特定の媒体について結晶粒径の分布解析と 組成解析を行うことか望ましい，CoCrTa面内磁詾記録媒体て粒 径と組成観察を行った結果力報告されているが22 現在実用化され ているCoCrPt-SiOx系垂直媒体て磁生結晶粒レベルの粒径と組 成を対比させて比較を行った研究は報告されていない，本研究で は，組成分析機能付きのTEMを用いて, $100 \mathrm{~Gb} / \mathrm{in}^{2}$ クラスの記録 密度能力を持つ垂直磁気記録媒体について結晶粒レベルの粒径と 組成の分布を調へた，個々の磁生結晶粒力磁気的に分離している と仮定し，さらに組成から結晶粒ごとの $K_{\mathrm{u}}$ ，飽和磁化 $M_{\mathrm{s}}$ および 異方性磁界 $H_{\mathrm{k}}$ を検討した，個々の結昌粒に対する

$K_{\mathrm{u}} V / \mathrm{k} T$ を検䛉した，結晶粒ごとの $K_{\mathrm{u}} V / k T$ 为結晶粒径に対し てどのように分布しているか検討を行った .

\section{2. 実験方法}

観察試料として , マグネトロンスパッタ法により形成した保護 膜:[CoCrPt-SiOx(膜厚 $12 \mathrm{~nm})] / \mathrm{Ru}$ 層下地層/glass基板 の構造を 持つ試作媒体試料を用いた。機械研磨とイオンミリング去により

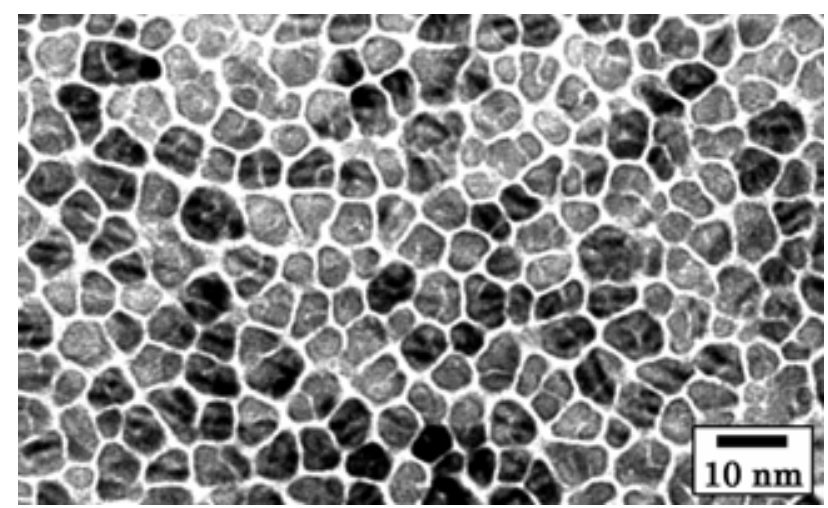

Fig. 1 Plan-view TEM image of CoCrPt-SiOx medium.
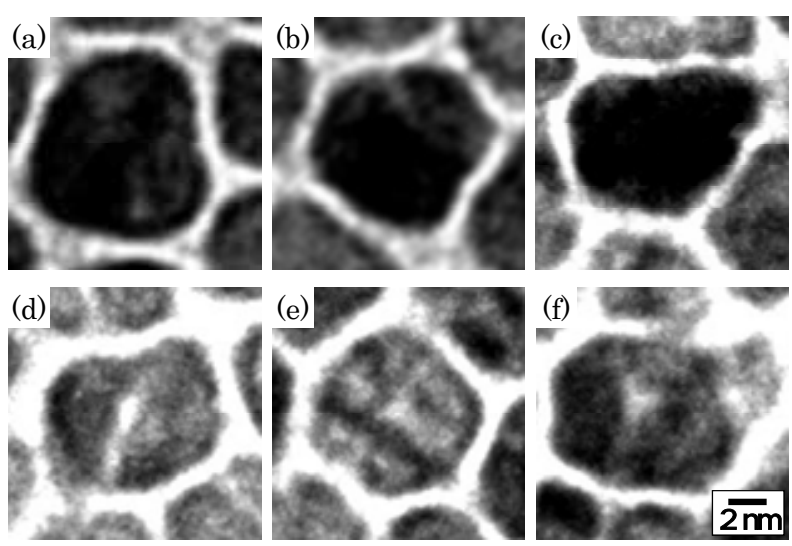

Fig. 2 Plan-view TEM image examples of magnetic crystal grains. (a)-(c) Uniform contrast grains, and (d)-(f) irregular contrast grains. 


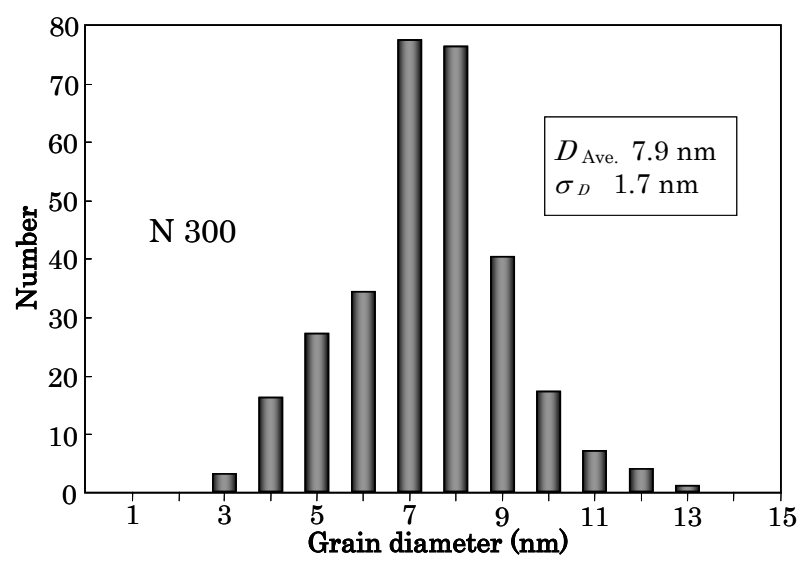

Fig. 3 Grain diameter distribution of the CoCrPt-SiOx medium.

磁生層を中心に薄膜化処理を行った。〈さび形の薄膜式料におい て 記録層と Ru中間層が含まれる領或を中心にTEM 観察を行っ た，磁生層を構成する結晶粒の結晶粒径解析と組成観察ては加速 電圧 $200 \mathrm{kV}$ のTEM を用いた． 組成分析ではTEMに付属する エネルギー分散型 $\mathrm{X}$ 線分析装置 (EDX) を活用した．EDX 測定

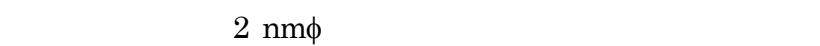
結晶粒組成を測定した．観察中の電子線およひ試料位置変動の影 響を低减するため，測定時間は 10 秒とした．Fig. 1 に磁生層の平 面 TEM 像例を示す．コントラストの黑し部分か磁生結晶粒，白 に細し連続した部分か粒界に相当する。磁性結晶粒を詳細に観察 すると , Fig. 1 (a)-(c)に示すようにコントラストが樣な結晶粒の 他に , 結晶粒内に白いコントラストか存在する結晶粒 (Fig. 2 (d)-(f) ) か存在することが分かった 。これらの結晶粒内部には TEM 観察て白いコントラストを与える粒界部と類似の非晶質酸 化物などが价在していることか想定される . Fig. 2(d)-(f)の例に示 すように，このような結晶粒は TEM 明視野像て明確に識別する ことができる．今回の観察ては, コントラストが樣な結晶粒を 均質結晶粒, 粒内に白いコントラストか認められた結晶粒を不均 質結晶粒として定義し，区別して組成分析を行なった。これら一 連の測定てはくさび形 TEM 試料の磁生層膜厚が少ない部分の測 定を避けるため，磁生層の膜厚方向全体の組成を得られる下地層 のRuカ検出された領或を抽出して行った .また，不均質結晶粒の EDX 組成分析では,粒中心部付近の白いコントラストの領域を中 心に約 $2 \mathrm{~nm} \phi に$ 絞った電子線を照射して測定を行った。

\section{3. 実験結果及び考察}

\section{1 結晶粒径および結晶粒体積}

平面TEM像から磁性結晶粒 300 個を抽出し,結晶粒径を測定し た。なお，この測定ては均質結晶粒と不均質結晶粒を区別せず， 一定のTEM視野内に含まれる結晶粒について行った . 結晶粒径と 頻度の関係をFig. 3 に示す。この観察試料の平均粒径は $7.9 \mathrm{~nm}$ ，

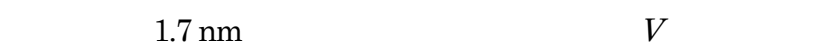
係を同樣に求めた。平均結晶粒体積は $615.6 \mathrm{~nm}^{3}$, 弚の標準偏差 は $261.7 \mathrm{~nm}^{3}$ であった .
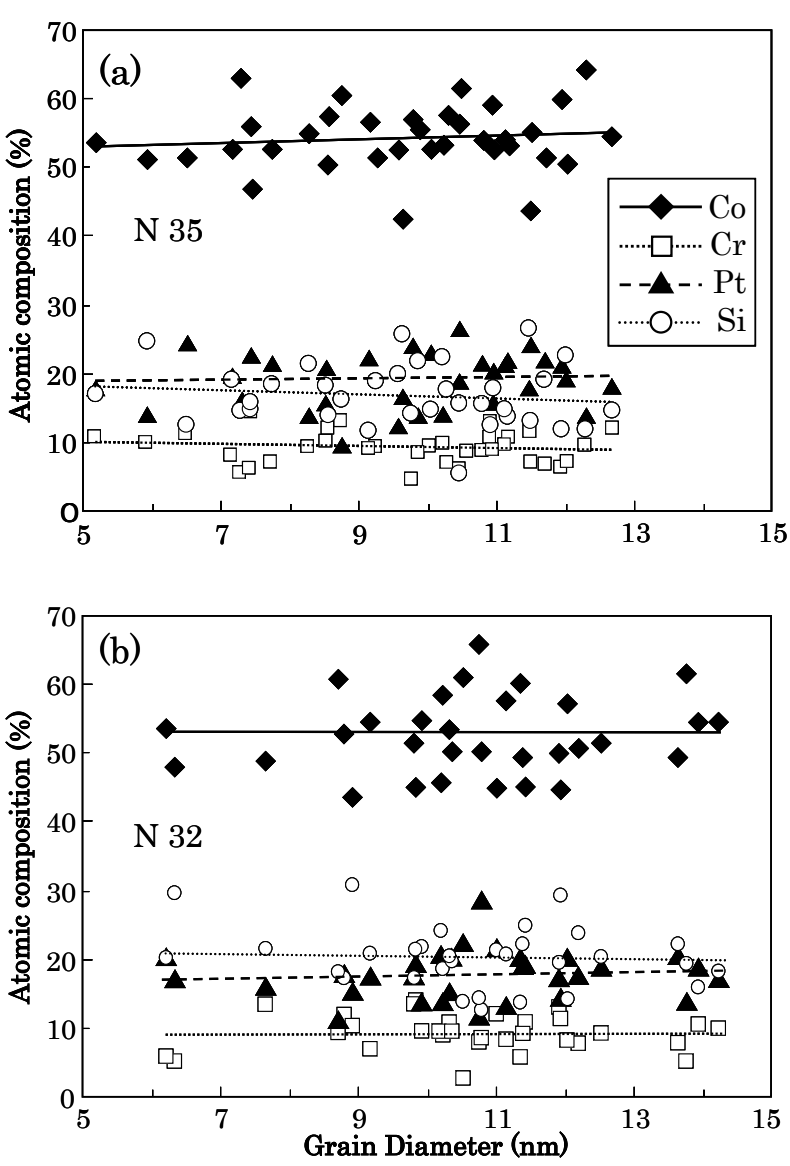

Fig. 4 Dependence of the composition on the grain diameter. (a) Uniform contrast grains. (b) Irregular contrast grains.

\section{2 結晶粒の組成}

結晶粒の組成則定は，均質結晶粒と不均質結晶粒を区別して行 った．Fig. 4 (a)は均質結晶粒 35 個 ，Fig. 4 (b)は不均質結晶粒 32 個につてて乥れぞれ結晶粒径と組成の関係を調へた結果である。 均質結晶粒の場合， $\mathrm{Co}, \mathrm{Cr}, \mathrm{Pt}, \mathrm{Si}$ 各原子組成比の平均は 54.2 , $9.4,19.4,17.0$ at.\%であり 標準偏差は光れ光れ $4.64,2.54,3.89$ ， 4.41 at.\%であった . 図中の直線と破線は最小二乗法により得られ た各元素組成の近似線である。 $\mathrm{Co}, \mathrm{Cr}, \mathrm{Pt}, \mathrm{Si}$ の各組成に対す

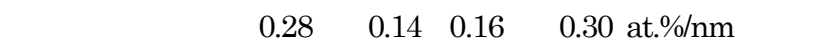
た． 磁生結晶粒の構成元素は, 結晶粒径力䊩大するにつれて Co と Pt濃度がわずか増加し, 逆に $\mathrm{Cr}$ と Pt濃度が減少する傾向が 認められる.ただ，これらの組成变化は Fig. 4(a)に示されるよう に結晶粒径が $5 \mathrm{~nm}$ 〜 $13 \mathrm{~nm}$ まて变化してもいずれも 2.4 at.\%以下 と小さいことが分かる.

一方, 不均質結晶粒 32 個の場合, $\mathrm{Co}, \mathrm{Cr}, \mathrm{Pt}, \mathrm{Si}$ 各原子組成 比の平均値は光れ光れ $52.8,9.2,17.7,20.3$ at.\%であった . 標

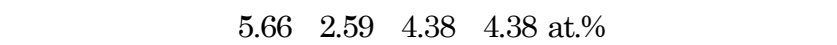
最小二乗法により得られた近似線の傾きは弚れ光れ， $0.08,0.08$ ， $0.19,-0.18$ at.\%/nm となった。 . 不均質結晶粒の場合, 結晶粒径 か増大するにつれて, Co と $\mathrm{Si}$ がずかに減少するのに対し, $\mathrm{Cr}$ 

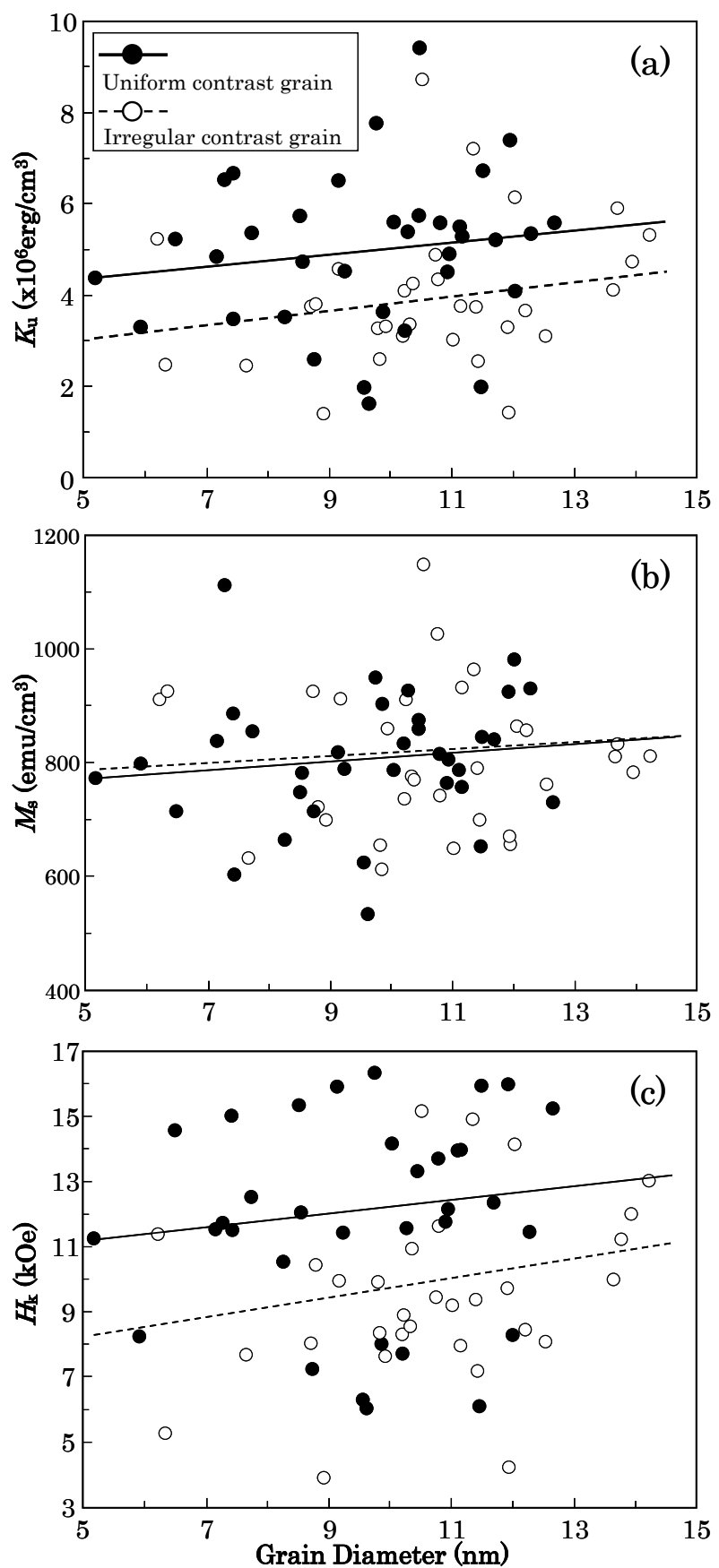

Fig. 5 Dependence of the magnetic properties on the crystal grain diameter. (a) uniaxial anisotropy constant $K_{\mathrm{u}}$ (b) saturation magnetization $M_{\mathrm{s}}$. (c) anisotropy field $H_{\mathrm{k}}$.

とPtか幾分増大する傾向力認められる、ただ，不均質結晶粒の粒 径に対する組成变化が最も大きい $\mathrm{Si}$ でも光の变化率は -0.18 at.\%/nm で,均質結晶粒の変化率 -0.30 at.\%/nm の $60 \%$ 程度に止 まっている．不均質結晶粒と均質結晶粒の平均組成を比較すると， 不均質結晶粒は均質結晶粒に比へて Co と Ptが学れ光れ 1.4 at.\% と 1.7 at.\%減少し, $\mathrm{Si}$ が3.3 at.\%増加していることが分かる.こ の差は，乥れ光れ 30 個以上の結晶粒について測定した組成の平均 値差であり，標隼偏差の範囲内ではあるが，有意差とみなすこと かできる.この組成差は，不均質結晶粒の TEM 像で白いコント

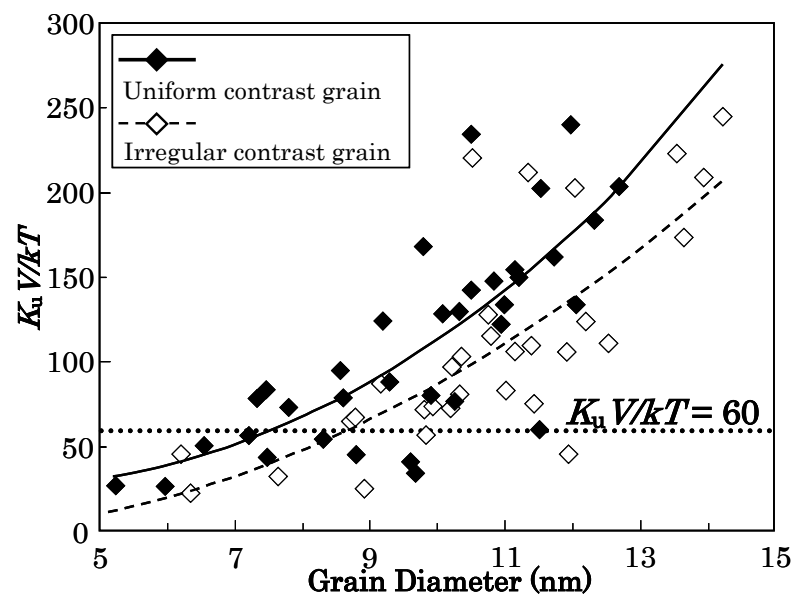

Fig. 6 Dependence of $K_{\mathrm{u}} V / k T$ on the crystal grain diameter.

ラスト領域として観察された部分で, Co と Pt が咸少し, 逆に $\mathrm{Si}$ か偏在していることを示していると解釈できる．Si力想定より幾 分高めの值として計測されているのは,TEMサンプル内ての電子 線散乱によって粒界部の信号を拾っている可能性, 薄膜の表面に 極薄の酸化物などか存在している可能性, および TEM サンプル 作製時起因のバックグラウンド信号による底上け効果か慟いてい る可能性がある.これらの量を定量的に確定することはできなか つたので, 今回のデータには底上げ分が含まれている可能性を否 定できない，ただし，仮に底上げによって $\mathrm{Si}$ の相対濃度力湢加し ているとしても，増加した分は，測定粒子 (測定点) ごとに大き 〈変化しないと考えられるため, 粒界でSi が多く, 粒内にも少し 存在するという構造には変わりない，また，組成の分散に対する 影響は小さいと考えられる．なお，今回の EDX による結晶粒内 の組成測定ては, 酸素 $(O)$ 濃度は測定箇所による値のばらつきが 大きく，測定の再現性と十分な精度を得ることかできなかった． 結晶粒内, 特に不均質結晶粒内には $\mathrm{Si}$ と共有結合しやすし酸素が 含まれることか泪定されるため，今後軽元素測定に適した EELS 法による解析を適用し，更に詳細な組成分析を行う必要がある。

\section{$3.3 K_{\mathrm{u}}, M_{\mathrm{s}}, H_{\mathrm{k}}$ の分布}

結晶粒径と組成の関伱力明らかになったので, 結晶粒ごとの $K_{\mathrm{u}}$ 值の算出を試みた ．ただ，今回扱つた磁生膜組成と $K_{\text {u值 }}$ 関係 を示す直接的なデータは無いため,ここでは測定した結晶粒組成

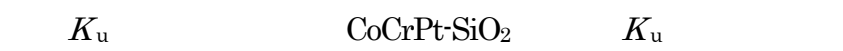
定した研究結果13) を参照した。この場合，以下のようにみなし

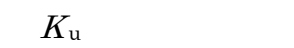

（1）磁生膜に含まれるSil，Co合金に固溶している場合や, 酸素 欠損酸化物の $\mathrm{SiO}_{\mathrm{x}}$ として実際には存在すると思われるが， 文献データを参照するために, 全て $\mathrm{SiO}_{2}$ として存在してい るものとみなしている .

(2) 文献131に示されている垂直磁化膜の下地, 膜厚構成あるいは膜 形成条件は本研究で用いた-媒体と異なっている. 同じ組成磁生膜 でもこれ等の条件か潩なると $K$ 值力若干変化することか知られ ているが, $K$ u值のこのような微妙な変化は考慮しない. 従って, 
ここて検討する $K$ u值には , ある程度の誤差が含まれることになる が, 記録某体を構成する磁性結晶粒の分布を反映したミクロレベ ルの $K$ u值の分散を議論する上ては有効と思われる .

Fig. 5 (a)にこの樣に考えて求めた磁生結晶粒径と $K$ u值の関係 を示す．この図より明らかなように，結晶粒径の増大とともに $K$ u值か渃干増大することが分かる．均質結晶粒に対する傾きは $0.13 \times 10^{6} \mathrm{erg} / \mathrm{cm}^{3} / \mathrm{nm}$ ，不均質結晶粒に対する傾きは $0.16 \times 10^{6}$ $\mathrm{erg} / \mathrm{cm}^{3} / \mathrm{nm}$ てほぼ同棣である。また，均質結晶粒と不均質結晶粒

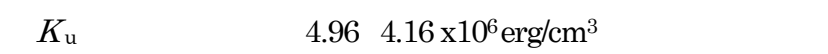

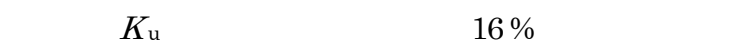

また，Kuの場合と同樣に考えて，結晶粒の組成から文献(4) を参 照して, 飽和磁化 $M_{\mathrm{s}}$ を算出した。粒径と $M_{\mathrm{s}}$ の関係をFig. 5 (b) に示す．均質結晶粒に対する傾きは $7.63 \mathrm{emu} / \mathrm{cm}^{3} / \mathrm{nm}$, 不均質結 晶粒に対する傾きは一 $0.68 \mathrm{emu} / \mathrm{cm}^{3} / \mathrm{nm}$ であった．これらの結果 から，均質結晶粒も不均質結晶粒も光の $M_{\mathrm{s}}$ は結晶粒径に大きく依 存しないことか分かる. $M_{\mathrm{s}}$ の平均は均質結晶粒と不均質結晶粒

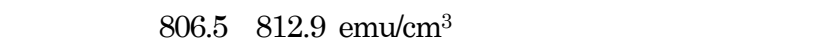
質結晶粒でMsに大きな差は見られない．

そとて Fig. $5(\mathrm{a})$,(b)の結果をもとに $H_{\mathrm{k}}=2 \cdot K_{\mathrm{u}} / M_{\mathrm{s}}$ の関係式 より $H_{\mathrm{k}}$ を算出した . 粒径と $H_{\mathrm{k}}$ の関係をFig. $5(\mathrm{c})$ に示す． 結晶粒 径の増大とともに， $H$ k力若干増大することが分かる．均質結晶 粒と不均質結晶粒に対する傾きは光れ光れ $2.11,4.05 \mathrm{kOe} / \mathrm{nm} て ゙$ あり，均質結晶粒よりも不均質結晶粒の方が $H_{\mathrm{k}}$ の粒径衣存性が少

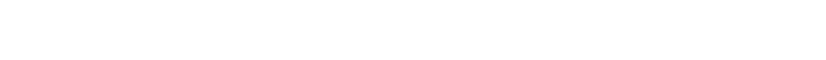

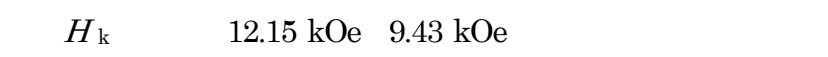
の $H_{\mathrm{k}}$ の值は均質結晶粒と比べ $15 〜 35 \%$ 程度低くなる傾向か沶さ れた.

\section{$3.4 K_{\mathrm{u}} V / k$ T T分布特性}

Fig. 5 (a)に示したデータを用いて，個々の結晶粒径に対 する $K_{\mathrm{u}} V / \mathrm{k} T$ 值の分布傾向を検討した． 結果をFig. 6 に示 す．ここでは温度 $(T)$ として $300 \mathrm{Kを}$ 用いた．磁性結晶 粒が互いに磁気的に分離していると考えると，均質結晶粒 の場合では結晶粒径が約 $7.5 \mathrm{~nm}$ 以上であれば媒体の熱的 安定性の目安とされている $K_{\mathrm{u}} V / k T>60$ を超えていること が分かる．一方，不均質結晶粒では均質結晶粒に比へて $K_{\mathrm{u}} V / k T$ 值が 20〜35\%程度低下しており， $K_{\mathrm{u}} V / k T>60$ を 越える結晶粒径は約 $8.7 \mathrm{~nm}$ に増大していることが分かる. これらの結果は媒体の熱的安定性には粒径の小さな均質結 晶粒とともに不均質結晶粒の影響が無視できないことを示 しているものと解棌される .

\section{$3.5 K_{\mathrm{u}} V / k \pi$ 対する $K_{\mathrm{u}}$ とに影響}

磁性結晶粒力磁気的に分離している場合， $K_{\mathrm{u}} V / k T$ 值は 温度 $(T)$ が一定の場合, 結晶粒の $K$ u値と体積 $(V)$ の変 動に影響される。 $K_{\mathrm{u}}$ 值は結晶粒組成に，V值は結晶粒径に 光れ依存する。本研究で害施した，磁性結晶粒の組成 と粒径の分布の測定結果をもとに, 両者の要因が $K_{\mathrm{u}} V / k T$ 值の分布に与える影響の程度を検討する．均質結晶粒 35 個について測定した結晶粒体積分散比 $\left(\sigma V / V_{\text {Ave }}\right)$ は 0.37 で
あり，不均質結晶粒 32 個で測定した結晶粒体積分散比は 0.35 であった．一方，組成のばらつきに起因する $K$ u分散 比 $\left(\sigma \mathrm{Ku} / K_{\mathrm{u}}\right.$ Ave.) は均質結晶粒では 0.34 , 不均質結晶粒で は 0.37 であった．これを考慮して， $K_{\mathrm{u}} V / \mathrm{k} T$ 值の分散に 及ぼす $K$ uと $V$ の分散比割合を百分率で表すと，均質結晶粒 の場合 48 対 52 , 不均質結晶粒に対しては 51 対 49 となる. この結果は, 結晶粒レベルでの $K_{\mathrm{u}} V / k T$ 值のばらつきは $K_{\mathrm{u}}$ と友方のばらつきにほぼ同程度の影響を受けていること を示している。

また，均質結晶粒と不均質結晶粒を比べた場合， $K_{\text {uおよ }}$ びK $K_{\mathrm{u}} V / k T$ 結晶粒径依存性が異なり，不均質結晶粒の場合，

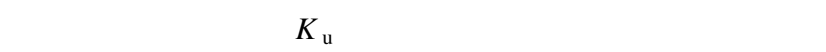
結晶粒内にSiを多く含む酸化物などが閉じ込められている と解釈される不均質結晶粒の存在が，磁気記録媒体を構成 する磁性結晶粒の $K_{\mathrm{u}}$ 分散，ひいては $K_{\mathrm{u}} V / k T$ 值の分散を増大 させていることが明らかになった .

\section{4. まとめ}

$\mathrm{CoCrPt}-\mathrm{SiOx}$ 垂直磁入記録媒体を構成する磁生結晶粒ごとの粒 径と組成を，組成分析機能を供えたTEMて調へた。明らかになっ た事項は以下の通りである。

[1] 観察した垂直媒体の結晶粒径は3 14 nmの範囲に分布してお り, 平均粒径 $7.9 \mathrm{~nm}$, 標準偏差 $\sigma=1.7 \mathrm{~nm}$ であった。

[2] 平面TEM像により，均質なコントラストを示す磁性結晶粒の 外に中心部泊く観察される不均質結晶粒力存在した .

[3] 磁生結晶粒の組成は，均質結晶粒と不均質結晶粒のいずれの場 合も多少の結晶粒径衣存性が見受けられた。均質結晶粒ては, 結 晶粒径力増大するにつれ，Co と Ptはわずかり増加し，Si は若干 減少する傾向があられた。

[4] 不均質結晶粒は均質結晶粒に比べ, Co, Pt の濃度が低 く, Si の組成比か増加している傾向が認められた .

[5] $K_{\mathrm{u}}, H_{\mathrm{k}}$ は結晶粒径の増大とともに若干増加する傾向が 認められた .

[6] 不均質結晶粒は均質結晶粒に比べ， $K$ 約 $16 \%, H_{\mathrm{k}}$ が 15 35\%程度, 光して $K_{\mathrm{u}} V / k T$ 值が $20 \sim 35 \%$ 程度相対的に低 くなっている傾向か認められた .

[7] 磁性結晶粒の $K \mathrm{u} V / \mathrm{k} T$ 值のばらつきには, 結晶粒径と組 成のばらつきが同程度の影響を及ばしている．

[8] 不均質結晶粒の存在により， $K$ uおよび $K_{\mathrm{u}} V / \mathrm{k} T$ 值の分 散が増大している。

謝辞 日立製作所中央研究所の平山義幸主任研究員, 五十嵐万壽 和主任研究員, 添谷進博士に研究手法や技術に関し助言を頂きま した こここに感敫致します。

\section{References}

1) M. Futamoto, N. Inaba, Y. Hirayama, K. Ito, and Y. Honda: $J$. Mag, Mag, Mater., 193, 36 (1999).

2) Y. Takahashi, K. Tanahashi, and T. Hosoe: J, Appl. Phys., 91, 8022 (2002).

3) D. E. Laughlin, S. Kumar, Y. Peng, and A. G. Roy: IEEE Trans. Magn., 41, 719 (2005). 
4) Y. Hirayama, M. Futamoto, K. Kimoto, and K. Usami: IEEE Trans. Magn., 32, 3807 (1996).

5) N. Inaba and M. Futamoto: J, Appl. Phys., 87, 6863 (2000).

6) N. Inaba and M. Futamoto: IEEE Trans. Magn., 36, 54 (2000).

7) N. Inaba, Y. Uesaka, and M. Futamoto: IEEE Trans. Magn., 36, 54 (2000).

8) J-G. Zhu, Y. Peng, and D. E. Laughlin: IEEE Trans. Magn., 41, 543 (2005).

9) M. Igarashi, Y. Hosoe, Y. Yahisa, Y. Matsuda, J. Inagaki, K. Furusawa, and S. Narishige: IEICE technical report., 496, 1 (1995).

10) S. Narishige and Y. Suzuki: J. Magn, Soc. Jpn., 25, 1647 (2001).
11) S. N. Piramanayagam, C. K. Pock, L. Lu, C. Y. Ong, J. Z. Shi, and C. S. Mah: Appl. Phys., 89, 162504 (2005).

12) J. F. Al-Sharab, J. Witting, J. Bentley, N. Evans, G. Bertero, and T. Yamashita: Digest of Intermag 2006., FW-10, 703 (2006).

13) T. Shimatsu, H. Sato, T. Oikawa, Y. Inaba, O. Kitakami, S. Okamoto, H. Aoi, H. Muraoka, and Y. Nakamura: IEEE Trans. Magn., 41, 566 (2005).

14) T. Shimatsu, H. Sato, T. Oikawa, Y. Inaba, O. Kitakami, S. Okamoto, H. Aoi, H. Muraoka, and Y. Nakamura: IEEE Trans. Magn., 40, 2483 (2004).

2007年10月4日受理，2008年2月14日採録 